\title{
Factors associated with depression, anxiety and stress among dentists during the COVID-19 pandemic
}

\author{
Cristiane de Melo ALENCAR(a) \\ Aryvelto Miranda SILVA(a) iD \\ Lucas Alves JURAL(b) iD \\ Marcela Baraúna MAGNO(b) \\ Edson Alves de CAMPOS(a) ID \\ Cecy Martins SILVA(c) iD \\ Raildo da Silva COQUEIRO(d) iD \\ Matheus Melo PITHON(b) ID \\ Lucianne Cople MAIA(b) ID \\ (a) Universidade Estadual Paulista - Unesp, \\ Faculty of Dentistry, Department of \\ Restorative Dentistry, Araraquara, SP, Brazil. \\ (b) Universidade Federal do Rio de Janeiro - \\ UFRJ, School of Dentistry, Department of \\ Pediatric Dentistry and Orthodontics, Rio de \\ Janeiro, RJ, Brazil. \\ (c) Universidade Federal do Pará - UFPA, \\ School of Dentistry, Department of Dental \\ Clinic, Belém, PA, Brazil. \\ (d) Universidade Estadual do Sudoeste da \\ Bahia - UESB, Center for Studies in Aging, \\ Jequié, BA, Brazil.
}

Declaration of Interests: The authors certify that they have no commercial or associative interest that represents a conflict of interest in connection with the manuscript.

\section{Corresponding Author:}

Lucianne Cople Maia

E-mail:maia_lc@odonto.ufri.br

ht1ps://doi.org/10.1590/1807-3107bor-2021.vol35.0084

Submitted: March 19, 2021

Accepted for publication: June 2, 2021

Last revision: June 24, 2021
Abstract: The objective of this work was to evaluate the relationship between factors associated with the COVID-19 pandemic and depression, anxiety, and stress (DAS) in dentists. Factors associated with the COVID-19 pandemic were evaluated using a questionnaire and scores of the Depression, Anxiety, and Stress Scales-21 were measured. The differences between the DAS scores based on the factors associated with the COVID-19 pandemic were tested through the successive application of multivariate analysis of variance (MANOVA, $\alpha=0.05$ ). After a sample size calculation, 998 participants with a mean age of $39.39( \pm 11.69)$ years were included. The effect size indicated that changes in sleep quality $(\eta 2=0.161)$, eating habits $(\eta 2=0.057)$, and physical health $(\eta 2=0.051)$ were the ones that most negatively affected DAS scores. The highest DAS scores were observed in professionals who lived with someone at high-risk for COVID-19 ( $p<0.001)$ and in those who did not engage in leisure activities during the pandemic $(p<0.001)$. Dentists who worked on the frontline against COVID-19 had higher scores of anxiety and stress $(p=0.029)$. The highest scores for anxiety, depression, and/ or stress were seen in dentists living with someone at high-risk for COVID-19, who acts on the frontline, who does not practice in leisure activities during the pandemic, who completely changed eating habits, quality of sleep and physical health during the pandemic. In general, DAS levels of dentists were associated with factors related to the COVID-19 pandemic.

Keywords: COVID-19; Depression; Anxiety; Stress, Psychological; Dentists.

\section{Introduction}

According to the COVID-19 panel of the Center for Systems Science and Engineering at Johns Hopkins University, in August 2020, Brazil was the second country in the world with the largest number of confirmed cases with more than 120 thousand deaths, second only to the United States. ${ }^{1}$ In addition, the World Health Organization situation reports for the month of July 2020 showed that Latin America was the new epicenter of the COVID-19 pandemic in the world, with Brazil reporting the highest number of cases and deaths in the region. ${ }^{2}$ 
Although several studies have demonstrated the effectiveness of social distancing in controlling the spread of COVID-19, ${ }^{3-6}$ Brazil is a continental country with urban characteristics-such as large low-income urban conglomerates ${ }^{7}$ and a large number of informal and unemployed workers ${ }^{8}$-that hinder the effectiveness of social distancing in controlling the spread of the virus.

In addition, the COVID-19 pandemic showed an important impact on health-related quality of life in different population groups. ${ }^{9,10}$ A study carried out in China showed that the risk of discomfort and anxiety/depression was significantly increased in the older population with chronic diseases and/or lower income during the pandemic. ${ }^{9}$ Another study evaluated the psychological health of healthcare professionals who treated patients with COVID-19 and showed that these professionals showed worse sleep quality, higher anxiety, and severe depressive symptoms during the pandemic..$^{10}$ Although health professionals worldwide have received updated guidance on biosafety protocols, they are under a lot of pressure at the workplace, ${ }^{11}$ as many are on the frontline of the pandemic in direct and close contact with infected patients.

Dental health professionals are in close proximity with patients during clinical care. In addition, for dental procedures that generate a large amount of droplets and aerosols, biosafety measures might be less effective in preventing the spread of COVID-19.12 A previous study recommended that testing for COVID-19 in dental professionals be carried out with the same priority as testing in hospital healthcare professionals. ${ }^{13}$ Possibly, the high risk of contamination in the daily lives of dental professionals can affect their psychological health. However, no study has been conducted to date to verify the relationship between factors related to the COVID-19 pandemic and the psychological health of dentists in a given country during the COVID-19 outbreak. Thus, the aim of this nationwide cross-sectional survey was to evaluate the relationship between factors associated with the COVID-19 pandemic and depression, anxiety, and stress (DAS) in Brazilian dentists during the period that the COVID-19 pandemic epicenter was Latin America. The null hypothesis was that there is no relationship between the factors associated with the COVID-19 pandemic on dentists' DAS.

\section{Methodology}

This nationwide cross-sectional survey was evaluated and approved by the ethics committee on human research of the local University (protocol number: 4.062.728). The research database and the questionnaire in the original language, were published in an open source platform (doi: 10.17605/OSF.IO/ U4KTB). The reporting guidelines for the SUrvey Reporting GuidelinE (SURGE) were consulted. ${ }^{14}$

The questions were based mainly on three key domains: a) Demographic and social characteristics; b) factors associated with the COVID-19 pandemic; and c) depression, anxiety, and stress assessed by a previously validated questionnaire(DASS-21). ${ }^{15}$ The questions were created by the authors and then evaluated by professionals.

\section{Evaluation by dentists}

Five dentists evaluated the questionnaire and were asked to make observations, changes, and suggestions, in addition to pointing out possible flaws.

\section{Evaluation by education and linguistic specialists}

Two professionals evaluated the questionnaire and were asked to make suggestions or corrections about possible difficulties in understanding the questions or response options.

\section{Evaluation by a psychiatrist}

A psychiatrist evaluated the questionnaire and was asked to make observations, modifications, and suggestions on each question so that the research objectives were adequately achieved.

\section{Evaluation by a statistician specialized in psychometrics}

the statistician was asked to make observations, modifications, and suggestions on each question so that the research objectives were adequately achieved.

Finally, the questionnaire was uploaded into the SurveyMonkey ${ }^{\odot}$ Inc. platform (San Mateo, USA) to be answered by the research volunteers. 


\section{Finalisation and application of the questionnaire}

\section{Questionnaire description}

To access the questionnaire, the participants had to read the informed consent form and agree to voluntarily participate in the research. The definitive questionnaire contained mandatory questions divided into three sections: a) demographic and social characteristics; b) factors associated with the COVID-19 pandemic, that is, being in the high-risk group for COVID-19, living with a health professional who works on the frontline against COVID-19, living with someone who is at high-risk for the disease, type of dental practice (on the frontline against COVID-19, only in private office, or not currently working), self-perception about being prepared for confronting COVID-19, opinion on social distancing measures, leisure activities, daily routine, physical health, eating habits, sleep quality, losing someone for COVID-19, financial issues, and undergoing psychotherapy; and c) depression, anxiety, and stress, evaluated by a previously-validated questionnaire (DASS - 21). ${ }^{15}$ The DASS-21 is a self-reported questionnaire that contains three subscales with a four-point scoring system $(0$, 1,2 , and 3), varying from 0 ("totally disagree") to 3 ("totally agree"). Each DASS subscale consists of seven items that assess DAS emotional states. The cutoff points for assessing the severity level were previously established by Lovibond and Lovibond ${ }^{16}$ and the total score is calculated by adding the subscale scores. In the final calculation, the total scores for each subscale were multiplied by two.

Sample calculation and participant recruitment

The sample size was calculated considering the following parameters: effect size f2 (Pillai's V) $=0.017$, $\alpha=0.05$, power $=0.95$, and number of response variables $=3$ (depression, anxiety, and stress). The effect size was defined by means of a preliminary analysis using data from a pilot study carried out on 100 selected dentists, respecting the stratification by dentists' numbers in each Brazilian region. Based on these parameters, a minimum sample size of 998 individuals was estimated. The sample size calculation was performed using the $G^{*}$ Power software
(Version 3.1.9.2, Germany), and the data from the pilot study did not compose the final sample.

A social media campaign targeting dentists from all over Brazil was created on Instagram ${ }^{\circ}$ (Facebook, Menlo Park, USA)..$^{17}$ The campaign started on July 11, 2020, and ran until July 30, 2020. Dentists were invited to participate in an online survey on their psychological health. In addition, individual invitations were sent through an online messaging application (Whatsapp ${ }^{\odot}$, Menlo Park, USA), by email, and disseminated by researchers on Facebook ${ }^{\odot}$ (Menlo Park, USA). In addition, participating researchers shared the invitations on their personal Instagram profiles (feeds and stories) and asked other dentists to help publicize the campaign. The virtual questionnaire was also circulated among dentist groups on the Whatsapp ${ }^{\odot}$ application. During the data collection period, the number of daily COVID-19 infection cases fluctuated in Brazil. The mean (M) and standard deviation (SD) of the number of cases during the collection period were $\mathrm{M}=40.414(\mathrm{SD}=16.104)$.

\section{Data analysis}

The data were tabulated and analyzed using IBM SPSS Statistics for Windows (IBM SPSS. 21.0, 2012; IBM Corp, Armonk, USA). Descriptive statistics were used to express the results as relative and absolute frequencies, means and standard deviations (SD), minimum and maximum values, and 95\% confidence intervals (95\% CI). The differences between the DAS scores based on factors related to the COVID-19 pandemic were tested through the successive application of multivariate analysis of variance (MANOVA). To classify the degree of DAS, a cutoff point based on the study by Lovibond and Lovibond ${ }^{16}$ was used. The threshold for statistical significance adopted in all analyses was $5 \%(\alpha=0.05)$.

\section{Results}

The age of the 998 participants ranged from 22 to 72 years, with a mean age of $39.39 \pm 11.69$ years and the average training time of $15.83 \pm 11.96$ years. The distribution of the participants according to sociodemographic and professional characteristics is shown in Table 1 . Table 2 shows the distribution 
Factors associated with depression, anxiety and stress among dentists during the COVID-19 pandemic

Table 1. Sociodemographic and professional characteristics of the sample.

\begin{tabular}{|c|c|c|}
\hline Variable & $n$ & $\%$ \\
\hline \multicolumn{3}{|l|}{ Sex } \\
\hline Female & 726 & 72.7 \\
\hline Male & 272 & 27.3 \\
\hline \multicolumn{3}{|l|}{ Age (years) } \\
\hline$\leq 31$ & 342 & 34.3 \\
\hline $32-44$ & 334 & 33.5 \\
\hline$>44$ & 322 & 32.3 \\
\hline \multicolumn{3}{|l|}{ Civil status } \\
\hline Single/without partner & 459 & 46.0 \\
\hline Married/with partner & 539 & 54.0 \\
\hline \multicolumn{3}{|l|}{ Region of work in Brazil } \\
\hline North & 57 & 5.7 \\
\hline Northeast & 169 & 16.9 \\
\hline Midwest & 90 & 9.0 \\
\hline Southeast & 519 & 52.0 \\
\hline South & 163 & 16.3 \\
\hline \multicolumn{3}{|l|}{ Region of work in the State } \\
\hline Capital & 489 & 49.0 \\
\hline Metropolitan region & 134 & 13.4 \\
\hline Interior & 375 & 37.6 \\
\hline \multicolumn{3}{|l|}{ Religion } \\
\hline Catholic & 614 & 61.5 \\
\hline Protestant/Evangelical & 107 & 10.7 \\
\hline Spiritist & 169 & 16.9 \\
\hline Others* & 108 & 10.8 \\
\hline \multicolumn{3}{|l|}{ Main income provider in the family } \\
\hline Yes, the only one & 199 & 19.9 \\
\hline Yes, together with someone else & 556 & 55.7 \\
\hline No & 243 & 24.3 \\
\hline \multicolumn{3}{|l|}{ Share housing } \\
\hline No & 89 & 8,9 \\
\hline Yes & 909 & 91,1 \\
\hline \multicolumn{3}{|l|}{ Time since graduation (years) } \\
\hline$\leq 7$ & 346 & 34.7 \\
\hline $8-20$ & 330 & 33.1 \\
\hline$>20$ & 322 & 32.3 \\
\hline \multicolumn{3}{|l|}{ Have specialization } \\
\hline No & 181 & 18.1 \\
\hline Yes & 817 & 81.9 \\
\hline
\end{tabular}

*Includes atheists and agnostics.

of the professionals according to factors related to the COVID-19 pandemic.

Table 3 shows the descriptive results of the depression, anxiety, and stress scores. The lowest
Table 2. Distribution of study participants according to factors related to the COVID-19 pandemic.

\begin{tabular}{lcc}
\hline Variable & $\mathrm{n}$ & $\%$ \\
\hline Are you in a high-risk group for COVID-19? & & \\
$\quad$ Yes & 207 & 20.7 \\
No & 791 & 79.3
\end{tabular}

Do you share residence with someone in the high-risk group for COVID-19?

$\begin{array}{lll}\text { Yes } & 420 & 42.1 \\ \text { No } & 578 & 57.9\end{array}$

Do you share residence with a frontline worker against COVID-19?

$\begin{array}{lcc}\text { Yes } & 133 & 13.3 \\ \text { No } & 865 & 86.7 \\ \text { Oork setting during the pandemic } & & \\ \text { On the frontline against COVID-19 } & 165 & 16.5 \\ \text { Private office } & 585 & 58.6 \\ \text { Not working } & 248 & 24.8 \\ \text { ow do you feel in confronting COVID-19? } & & \\ \text { Prepared } & 376 & 37.7 \\ \text { Unprepared } & 530 & 53.1 \\ \text { Don't know } & 92 & 9.2\end{array}$

Do you agree to maintain measures of social distance?

$\begin{array}{lcc}\text { No } & 38 & 3.8 \\ \text { Yes } & 696 & 69.7 \\ \text { Partially } & 264 & 26.5\end{array}$

Leisure activities during the pandemic

Active leisure $\quad 552 \quad 55.3$

$\begin{array}{lll}\text { Passive leisure } & 417 & 41.8\end{array}$

$\begin{array}{lll}\text { No activity } & 29 & 2.9\end{array}$

Change of daily routine during the pandemic No or little change $\quad 298 \quad 29.9$ $\begin{array}{lll}\text { Completely changed } & 700 & 70.1\end{array}$

Physical health during the pandemic

Worse/less healthy $\quad 512 \quad 51.3$

No change $\quad 355 \quad 35.6$

$\begin{array}{lll}\text { Better/healthier } & 131 & 13.1\end{array}$

Negative impact of the pandemic on food quality

$\begin{array}{lll}\text { No } & 435 & 43,6\end{array}$

$\begin{array}{lll}\text { Yes } & 340 & 34,1\end{array}$

$\begin{array}{lll}\text { Partially } & 223 & 22,3\end{array}$

Negative change in sleep quality during the pandemic

None/rarely $\quad 344 \quad 34.5$

$\begin{array}{lll}\text { Sometimes } & 361 & 36.2\end{array}$

Often/always $293 \quad 29.4$

Lost someone to COVID-19

$\begin{array}{lll}\text { No } & 726 & 72.7\end{array}$

$\begin{array}{lll}\text { Yes, relatives/friends } & 187 & 18.7\end{array}$

Yes, others $\quad 85 \quad 8.5$

Negative financial impact due to pandemic

Yes $\quad 525 \quad 52.6$

No $\quad 245 \quad 24.5$

$\begin{array}{lll}\text { Partially } & 228 & 22.8\end{array}$

Psychotherapy

Yes, but stopped during the pandemic $\quad 244 \quad 24.4$

$\begin{array}{lll}\text { Yes, continued during the pandemic } & 106 & 10.6\end{array}$

$\begin{array}{lll}\text { Neither before or during the pandemic } & 648 \quad 64.9\end{array}$ 
Table 3. Descriptive statistics of depression, anxiety and stress scores in Brazilian dentists during the COVID-19 pandemic.

\begin{tabular}{lcccc}
\hline Subscale & Mean & Standard deviation & $95 \% \mathrm{Cl}$ & Min-max \\
\hline Depression & 10.63 & 9.46 & $10.04-11.22$ & $0.00-42.00$ \\
Anxiety & 8.85 & 9.21 & $8.27-9.42$ & $0.00-42.00$ \\
Stress & 15.84 & 10.22 & $15.21-16.48$ & $0.00-42.00$ \\
\hline
\end{tabular}

mean score was observed for the anxiety subscale and the highest for the stress subscale.

The results showed that $47.3 \%$ (95\%CI: 44.16-50.45) of the participants reported experiencing some degree of depression, $46.3 \%$ (95\%CI: 43.17-49.45) anxiety, and 47.0\% (95\%CI: 43.87-50.15) stress.

MANOVA indicated that the following variables were not related to DAS scores: negative financial impact due to the pandemic $[\mathrm{F}(6,1988)=1.181$; $\mathrm{p}=0.314]$, living with a frontline health professional $[\mathrm{F}(3,994)=1,100 ; \mathrm{p}=0.348)$, being in the high-risk group for COVID-19 $[\mathrm{F}(3,994)=0.603 ; \mathrm{p}=0.613]$, losing someone to COVID-19 [F $(6,1988)=0.972$; $\mathrm{p}=0.443]$, and self-perceived preparedness to confront COVID-19 $[\mathrm{F}(6,1988)=1.871 ; \mathrm{p}=0.082]$.

Table 4 shows the variables that were associated with the DAS scores. The effect size analysis indicated that a negative change in the quality of sleep during the pandemic $(\eta 2=0.161)$, a negative impact of the pandemic on eating habits $(\eta 2=0.057)$, and physical health during the pandemic $(\eta 2=0.051)$ were, in that order, most negatively associated with the psychological health of dentists.

Table 5 shows the descriptive results and comparisons between the groups. Compared to their peers, higher DAS scores were observed in professionals who during the pandemic lived with someone at high-risk of COVID-19, did not engage in leisure activities, completely changed their daily routine, had a higher frequency of negative changes in sleep quality, and was undergoing or interrupted psychotherapy. Dentists on the COVID-19 frontline had higher scores of anxiety and stress, but not depression, compared to professionals working only in a dental office. Participants who agreed to social distancing measures had higher scores of depression (compared to those who did not agree and partially agreed), anxiety (compared to those who partially agreed), and stress (compared to those who did not agree). Dentists with worse physical health during the pandemic had higher scores of depression (compared to those who indicated health improvement), anxiety, and stress (compared to those without changes). Finally, dentists who reported worse eating habits during the pandemic had the higher scores for depression and stress.

\section{Discussion}

In general, the results of the present study showed that dentists' DAS levels were negatively impacted by factors related to the COVID-19 pandemic. For this reason, the null hypothesis was rejected. The highest scores for anxiety, depression, and/or stress were seen in dentists living with someone at high-risk of COVID-19, who were on the frontline against COVID-19, who agreed to social distancing measures, who did not engage in leisure activities during the pandemic, who completely changed their daily routine, eating habits, and quality of sleep during the pandemic, and undergoing psychotherapy.

The need for social isolation and other preventive measures has changed the way of life of most people around the world. In addition, the high risk of contagion, especially among health professionals, has introduced new habits in the professionals' work routine. ${ }^{3-6}$ This study showed that the negative effect of the COVID-19 pandemic on the quality of sleep of dentists negatively affected their DAS levels. Previous studies corroborate these findings, showing a strong relationship between sleep disorders and depression, ${ }^{18,19}$ anxiety, ${ }^{18,19}$ and stress. ${ }^{20,21}$ In addition, a recent systematic review showed that health professionals experienced increased symptoms of depression, anxiety, psychological distress, and poor sleep quality during the COVID-19 pandemic. ${ }^{22}$ Although some countries, such as Italy and Israel, have published studies related to this issue, ${ }^{23,24}$ no study was yet conducted to assess the effect of the COVID-19 pandemic on the psychological health of dentists in Brazil, which is at the moment, the second most affected country. 
Factors associated with depression, anxiety and stress among dentists during the COVID-19 pandemic

Table 4. Multivariate and univariate analysis of variance for depression, anxiety, and stress of Brazilian dental surgeons during the COVID-19 pandemic

\begin{tabular}{|c|c|c|c|c|c|}
\hline Variable & $\mathrm{F}$ & $\mathrm{DF}_{\mathrm{h}}$ & $\mathrm{DF}_{\mathrm{e}}$ & $\mathrm{p}$-value & $\eta^{2}$ \\
\hline Live with someone in the high-risk group for COVID-19 & 7.055 & 3 & 994 & $<0.001$ & 0.021 \\
\hline Depression & 13.549 & 1 & 996 & $<0.001$ & 0.013 \\
\hline Anxiety & 14.261 & 1 & 996 & $<0.001$ & 0.014 \\
\hline Stress & 21.151 & 1 & 996 & $<0.001$ & 0.021 \\
\hline Work setting during the pandemic & 2.353 & 6 & 1988 & 0.029 & 0.007 \\
\hline Depression & 2.709 & 2 & 995 & 0.067 & 0.005 \\
\hline Anxiety & 4.541 & 2 & 995 & 0.011 & 0.009 \\
\hline Stress & 3.679 & 2 & 995 & 0.026 & 0.007 \\
\hline Agrees to measures of social distance & 6.187 & 6 & 1988 & $<0.001$ & 0.018 \\
\hline Depression & 11.300 & 2 & 995 & $<0.001$ & 0.022 \\
\hline Anxiety & 16.410 & 2 & 995 & $<0.001$ & 0.032 \\
\hline Stress & 17.101 & 2 & 995 & $<0.001$ & 0.033 \\
\hline Leisure activities during the pandemic & 10.314 & 6 & 1988 & $<0.001$ & 0.030 \\
\hline Depression & 25.546 & 2 & 995 & $<0.001$ & 0.049 \\
\hline Anxiety & 22.026 & 2 & 995 & $<0.001$ & 0.042 \\
\hline Stress & 20.592 & 2 & 995 & $<0.001$ & 0.040 \\
\hline Change of daily routine during the pandemic & 9.662 & 3 & 994 & $<0.001$ & 0.028 \\
\hline Depression & 14.625 & 1 & 996 & $<0.001$ & 0.014 \\
\hline Anxiety & 16.711 & 1 & 996 & $<0.001$ & 0.017 \\
\hline Stress & 28.757 & 1 & 996 & $<0.001$ & 0.028 \\
\hline Physical health during the pandemic & 17.669 & 6 & 1988 & $<0.001$ & 0.051 \\
\hline Depression & 38.921 & 2 & 995 & $<0.001$ & 0.073 \\
\hline Anxiety & 41.016 & 2 & 995 & $<0.001$ & 0.076 \\
\hline Stress & 51.335 & 2 & 995 & $<0.001$ & 0.094 \\
\hline Negative impact of the pandemic on eating habits & 20.204 & 6 & 1988 & $<0.001$ & 0.057 \\
\hline Depression & 45.487 & 2 & 995 & $<0.001$ & 0.084 \\
\hline Anxiety & 32.045 & 2 & 995 & $<0.001$ & 0.061 \\
\hline Stress & 51.542 & 2 & 995 & $<0.001$ & 0.094 \\
\hline Negative change in sleep quality during the pandemic & 63.610 & 6 & 1988 & $<0.001$ & 0.161 \\
\hline Depression & 126.860 & 2 & 995 & $<0.001$ & 0.203 \\
\hline Anxiety & 141.638 & 2 & 995 & $<0.001$ & 0.222 \\
\hline Stress & 213.124 & 2 & 995 & $<0.001$ & 0.300 \\
\hline Psychotherapy & 7.906 & 6 & 1988 & $<0.001$ & 0.023 \\
\hline Depression & 17.645 & 2 & 995 & $<0.001$ & 0.034 \\
\hline Anxiety & 15.686 & 2 & 995 & $<0.001$ & 0.031 \\
\hline Stress & 23.586 & 2 & 995 & $<0.001$ & 0.045 \\
\hline
\end{tabular}

$\mathrm{DF}_{\mathrm{h}}$ : hypothesis degree of freedom; $\mathrm{DF}_{\mathrm{e}}$ : degree of freedom of error.

The use of validated questionnaires is important to obtain accurate results. Although the present study used a validated questionnaire to assess depression, anxiety and stress (DAS), the main study outcomes, it is important to highlight that changes on sleep quality were self-reported. Previously validated scales of sleep quality ${ }^{25}$ were not used since we evaluated sleep quality changes and thus it would be necessary to apply the scale before and after the pandemic. Our results corroborate with a previous longitudinal study performed with a validated questionnaire that indicated that a lockdown period due to COVID-19 had a negative impact on adults' sleep quality. ${ }^{26}$ However, the development of longitudinal 
Table 5. Means and standard deviations of the scores for depression, anxiety, and stress in Brazilian dental surgeons due to factors related to the COVID-19 pandemic.

\begin{tabular}{|c|c|c|c|c|c|c|}
\hline \multirow{2}{*}{ Variable } & \multicolumn{2}{|c|}{ Depression } & \multicolumn{2}{|c|}{ Anxiety } & \multicolumn{2}{|c|}{ Stress } \\
\hline & M & SD & M & SD & M & SD \\
\hline \multicolumn{7}{|c|}{ Live with someone in the high-risk group for COVID-19 } \\
\hline Yes & $11.91^{\circ}$ & 10.24 & $10.13^{a}$ & 9.84 & $17.57^{a}$ & 10.70 \\
\hline No & $9.70^{\mathrm{b}}$ & 8.74 & $7.91^{\mathrm{b}}$ & 8.61 & $14.59^{b}$ & 9.67 \\
\hline \multicolumn{7}{|l|}{ Work setting during the pandemic } \\
\hline On the frontlines against COVID-19 & 11.25 & 9.77 & $10.58^{a}$ & 9.95 & $17.21^{\mathrm{a}}$ & 10.98 \\
\hline Private office & 10.05 & 9.16 & $8.21^{\mathrm{b}}$ & 8.87 & $15.12^{b}$ & 9.67 \\
\hline Not working & 11.58 & 9.87 & $9.19^{\mathrm{ab}}$ & 9.37 & $16.63^{\mathrm{ab}}$ & 10.82 \\
\hline \multicolumn{7}{|l|}{ Agrees to measures of social distance } \\
\hline No & $8.47^{a}$ & 9.33 & $6.68^{\mathrm{ab}}$ & 9.33 & $12.63^{a}$ & 9.13 \\
\hline Yes & $11.56^{\mathrm{b}}$ & 9.75 & $9.93^{a}$ & 9.66 & $17.07^{b}$ & 10.49 \\
\hline Partially & $8.49^{a}$ & 8.27 & $6.30^{\mathrm{b}}$ & 7.25 & $13.08^{a b}$ & 8.94 \\
\hline \multicolumn{7}{|l|}{ Leisure activities during the pandemic } \\
\hline Active leisure & $8.97^{a}$ & 8.75 & $7.47^{a}$ & 8.42 & $14.52^{a}$ & 9.72 \\
\hline Passive leisure & $12.30^{\circ}$ & 9.66 & $10.11^{\mathrm{a}}$ & 9.49 & $16.93^{\circ}$ & 10.32 \\
\hline No activity & $18.21^{b}$ & 11.81 & $16.90^{\mathrm{b}}$ & 12.52 & $25.45^{b}$ & 11.34 \\
\hline \multicolumn{7}{|l|}{ Change of daily routine during the pandemic } \\
\hline No or little change & $8.89^{a}$ & 9.10 & $7.03^{a}$ & 8.08 & $13.22^{a}$ & 9.37 \\
\hline Yes, completely changed & $11.37^{b}$ & 9.52 & $9.62^{\mathrm{b}}$ & 9.55 & $16.96^{b}$ & 10.37 \\
\hline \multicolumn{7}{|l|}{ Physical health during the pandemic } \\
\hline Worse/less healthy & $13.11^{\mathrm{a}}$ & 9.88 & $11.31^{\circ}$ & 10.08 & $18.87^{a}$ & 10.27 \\
\hline No change & $8.09^{a b}$ & 7.93 & $6.03^{b}$ & 6.77 & $12.35^{b}$ & 8.99 \\
\hline Better/healthier & $7.82^{b}$ & 9.05 & $6.84^{\mathrm{ab}}$ & 8.77 & $13.50^{\mathrm{ab}}$ & 9.57 \\
\hline \multicolumn{7}{|c|}{ Negative impact of the pandemic on eating habits } \\
\hline No & $7.95^{\mathrm{a}}$ & 8.48 & $6.77^{\circ}$ & 8.19 & $12.53^{a}$ & 9.44 \\
\hline Yes & $14.21^{\mathrm{b}}$ & 10.14 & $11.89^{\mathrm{b}}$ & 10.27 & $19.64^{\mathrm{b}}$ & 10.45 \\
\hline Partially & $10.39 c$ & 8.39 & $8.25^{\mathrm{ab}}$ & 8.11 & $16.53^{c}$ & 9.18 \\
\hline \multicolumn{7}{|c|}{ Negative change in sleep quality during the pandemic } \\
\hline None/rarely & $6.20^{\circ}$ & 7.57 & $4.15^{a}$ & 6.05 & $9.24^{a}$ & 7.84 \\
\hline Sometimes & $9.84^{b}$ & 7.49 & $8.33^{\mathrm{b}}$ & 7.65 & $16.09^{b}$ & 8.08 \\
\hline Often/always & $16.80^{c}$ & 10.35 & $14.99^{c}$ & 10.50 & $23.28^{c}$ & 9.85 \\
\hline \multicolumn{7}{|l|}{ Psychotherapy } \\
\hline Yes, but stopped during the pandemic & $12.59^{a}$ & 9.86 & $10.79^{a}$ & 9.71 & $18.43^{a}$ & 10.05 \\
\hline Yes, continued during the pandemic & $13.83^{\circ}$ & 10.56 & $11.55^{\circ}$ & 10.62 & $19.55^{a}$ & 10.52 \\
\hline Neither before or during the pandemic & $9.37^{b}$ & 8.86 & $7.67^{b}$ & 8.54 & $14.26^{b}$ & 9.89 \\
\hline
\end{tabular}

M: mean; SD: standard deviation. ${ }^{a, b, c}$ Different letters in a column indicate statistical difference between groups (Tukey test).

studies to assess changes in dentists' sleep quality and their relationship to depression, anxiety, and stress during COVID-19 pandemic are recommended.

The deterioration of eating habits and physical health reported by dentists during the pandemic also showed a negative impact on DAS levels. It is possible that social isolation measures in quarantine influence people to adopt a more sedentary lifestyle and eat less healthy and out-of-hours food. ${ }^{27}$ Recently, 35 research organizations from Europe, North Africa, West Asia, and the Americas carried out research that investigated the effects of home confinement on individuals' eating behavior and physical activity during the COVID-19 pandemic. ${ }^{28}$ The authors showed that although social isolation is a necessary public health measure, it alters physical activity and 
eating habits in a way that can negatively affect the health of individuals.

Surprisingly, some important factors assessed in this study were not associated with anxiety, depression, and/or stress in dentists. Among them was the financial impact of the pandemic, being at risk of COVID-19, or losing someone to COVID-19. Although $52.6 \%$ of dentists experienced a negative financial impact during the pandemic, this factor was not associated with their psychological health. This could be related to the short duration and lack of the most restrictive measures of social isolation (such as lockdown) in Brazil. ${ }^{8}$ Dental services are essential activities and continued to be offered throughout Brazil, ${ }^{29}$ but with reduced patient flow. In addition, being at high-risk for COVID-19 or losing someone to the disease did not affect the DAS scores. A part of the Brazilian population does not believe in the severity of the disease, relaxing social isolation measures even though they are at risk. Although the dentists' political beliefs were not evaluated, it is possible that this behavior is related to the denial speeches of some Brazilian political authorities who, at various times, have downplayed the severity of the SARS-CoV-2 virus infection. ${ }^{8,30,31}$ On the other hand, the present study did not investigate the closeness of dentists to COVID-19 victims, regardless of whether they were related, which might have affected the results. The lack of knowledge of this variable could be a limitation of this study.

Although "being in the high-risk group" did not affect the psychological health of dentists, living with someone from the high-risk group was associated with negative changes in the DAS scores. This suggests a greater concern of the dentists for the health of their relatives and friends compared to their own health. In addition, dentists with no leisure activity during the pandemic also had higher DAS scores than those who did have them. Previous studies have shown that leisure activities are directly associated with psychological health, as they provide a sense of well-being and are low-cost strategies that improve individuals' health. ${ }^{32,33}$ However, leisure activities at home, during the sanitary demands of social distancing, are more limited and require creativity to develop constant dynamic activities without leaving home.
Dentists who were on psychological treatment before the pandemic had a more negative effect on psychological health during the pandemic when compared to those who never received psychotherapy, which could be related to the greater emotional fragility of the latter professionals. However, this study did not quantify the duration of prior or current psychological treatment. In addition, the COVID-19 pandemic sparked immediate psychological responses, ${ }^{34}$ which makes it difficult to draw a definitive conclusion about the negative effects on anxiety, depression, and/or stress in dentists who were already undergoing psychological treatment before the pandemic.

COVID-19 frontline dentists had the highest scores of anxiety and stress, but not of depression, when compared to private dentists. The diagnosis of depression or anxiety is associated with several symptoms that often overlap, ${ }^{35}$ while stress has been shown to be a risk factor for the development of anxiety and depression. ${ }^{36}$ Depression has characteristics such as hopelessness, low positive affect, low self-esteem, and low motivation. Anxiety, on the other hand, is associated with physiological hyperstimulation, while stress is caused by persistent tension, irritability, and low threshold for frustration. ${ }^{37,38}$ Stress is defined as an emotional experience associated with physiological, biochemical, cognitive, and behavioral events. ${ }^{15}$ Our findings are probably directly linked to emotional experiences of dentists during the pandemic. Although anxiety and stress can be causal factors for depression, ${ }^{18}$ in the present study, depression showed the lowest scores in frontline dentists, which is probably related to the greater complexity in the etiology of depression, involving environmental, genetic, and biological forces. ${ }^{39}$ These results should be reassessed at the end of the pandemic to verify the evolution of the psychological health of dentists. In addition, follow-up studies are encouraged to see whether professionals who have anxiety and stress will develop depression after some time.

Dentists who agreed with the social distancing measures demonstrated higher scores of depression when compared to those who disagreed or only partially agreed. It is possible that the participants who agreed with the social distancing 
measures are more concerned with the impacts of COVID-19 infection than those who did not agree. This might be associated with a higher level of depression, which is a more serious impact on individuals' mental health than anxiety and stress. ${ }^{18}$ In addition, those with worse physical health during the pandemic had higher scores of depression than those who reported improvement; this group also showed higher scores of anxiety and stress when compared to dentists who reported no change in physical health before and after the start of the pandemic. The worsening of physical health is possibly related to inactivity and decreased self-care during the pandemic. A meta-analysis conducted by Kvam et al. ${ }^{40}$ showed that physical exercise is an effective intervention against depression and can be a feasible supplementary treatment in combination with antidepressants. However, as a limitation, the present study did not ask volunteers for specific signs or symptoms that indicated worsening or improvement of physical health.

Brazil is a heterogeneous country, and measures to combat the COVID-19 pandemic are divergent among federal, state, and municipal governments. Thus, the incidence of cases and mortality rates for COVID-19 have a high variability among states ${ }^{41}$ and can have different effects on individuals' DAS. In this sense, having a national representative sample guaranteed a high accuracy of our findings. It is also important to consider the effects of the variability of epidemiological indicators throughout the pandemic and the uncertainty of when it will end. The current scenario indicates that the pandemic will continue to have a major impact on human life in the medium-term in Brazil ${ }^{42}$, and its cumulative effect on the psychological health of individuals should be further investigated in the country and worldwide. Public policies to minimize the psychological trauma in dentists during the pandemic are encouraged, ideally planned and carried out by public bodies and regional boards (Regional Councils of Dentistry) and possibly around the world.

\section{Conclusion}

In general, higher DAS levels of dentists in Brazil are associated with factors related to the COVID-19 pandemic. The highest scores for anxiety, depression, and/or stress were seen in dentists living with someone in the high-risk group for COVID-19, working on the pandemic frontline, who agree with social distancing measures, with no leisure activities during the pandemic, who completely changed their daily routine, eating habits, and quality of sleep during the pandemic, and were undergoing psychotherapy before the pandemic. However, as the COVID-19 pandemic is ongoing, our results need to be confirmed in future population-based studies around the world.

\section{Acknowledgments}

We appreciate the valuable contribution of Lucas Campos and Luiz Guilherme in the design of our study. This study was financed in part by the Coordination for the Improvement of Higher Education Personnel Government of Brazil (Capes) - Finance Code 001. The funders had no role in study design, data collection and analysis, decision to publish, or preparation of the manuscript. All authors declare no conflicts of interest in this study.

\section{References}

1. Johns Hopkins University. Coronavirus Resource Center. COVID-19 dashboard by the Center for Systems Science and Engineering (CSSE) at Johns Hopkins University. 2020 [cited 2020 Aug 28]. Available from: https://coronavirus.jhu.edu/map.html

2. World Health Organization. Coronavirus disease (COVID-2019) situation reports. Situation report - 188 Coronavirus disease 2019. 2020 [cited 2020 July 27]. Available from: https://www. who.int/emergencies/diseases/novel-coronavirus-2019/situation-reports

3. Prem K, Liu Y, Russell TW, Kucharski AJ, Eggo RM, Davies N, et al. The effect of control strategies to reduce social mixing on outcomes of the COVID-19 epidemic in Wuhan, China: a modelling study Lancet Public Health. 2020 May;5(5):e261-70. https://doi.org/10.1016/S2468-2667(20)30073-6 
- Factors associated with depression, anxiety and stress among dentists during the COVID-19 pandemic

4. Kucharski AJ, Klepac P, Conlan AJ, Kissler SM, Tang ML, Fry H, et al. Effectiveness of isolation, testing, contact tracing, and physical distancing on reducing transmission of SARS-CoV-2 in different settings: a mathematical modelling study. Lancet Infect Dis. 2020 Oct;20(10):1151-60. https://doi.org/10.1016/S1473-3099(20)30457-6

5. Maclntyre CR. Case isolation, contact tracing, and physical distancing are pillars of COVID-19 pandemic control, not optional choices. Lancet Infect Dis. 2020 Oct;20(10):1105-6. https://doi.org/10.1016/S1473-3099(20)30512-0

6. Chu DK, Akl EA, Duda S, Solo K, Yaacoub S, Schünemann HJ, et al. Physical distancing, face masks, and eye protection to prevent person-to-person transmission of SARS-CoV-2 and COVID-19: a systematic review and meta-analysis. Lancet. 2020 Jun;395(10242):1973-87. https://doi.org/10.1016/S0140-6736(20)31142-9

7. Marson FA, Ortega MM. COVID-19 in Brazil. Pulmonology. 2020 Jul - Aug;26(4):241-4. https://doi.org/10.1016/i.pulmoe.2020.04.008

8. Aquino EM, Silveira IH, Pescarini JM, Aquino R, Souza-Filho JA, Rocha AS, et al. Social distancing measures to control the COVID-19 pandemic: potential impacts and challenges in Brazil. Cien Saúde Colet. 2020 June;25(suppl 1):2423-46. https://doi.org/10.1590/1413-81232020256.1.10502020

9. Ping W, Zheng J, Niu X, Guo C, Zhang J, Yang H, et al. Evaluation of health-related quality of life using EQ-5D in China during the COVID-19 pandemic. PLoS One. 2020 Jun;15(6):e0234850. https://doi.org/10.1371/journal.pone.0234850

10. Stojanov J, Malobabic M, Stanojevic G, Stevic M, Milosevic V, Stojanov A. Quality of sleep and health-related quality of life among health care professionals treating patients with coronavirus disease-19. Int J Soc Psychiatry. 2021 Mar;67(2):175-81 https://doi.org/10.1177/0020764020942800

11. Zhang WR, Wang K, Yin L, Zhao WF, Xue Q, Peng M, et al. Mental health and psychosocial problems of medical health workers during the COVID-19 epidemic in China. Psychother Psychosom. 2020;89(4):242-50. https://doi.org/10.1159/000507639

12. Meng L, Hua F, Bian Z. Coronavirus disease 2019 (COVID-19): emerging and future challenges for dental and oral medicine. J Dent Res. 2020 May;99(5):481-7. https://doi.org/10.1177/0022034520914246

13. Dave M, Seoudi N, Coulthard P. Urgent dental care for patients during the COVID-19 pandemic. Lancet. 2020 Apr;395(10232):1257. https://doi.org/10.1016/S0140-6736(20)30806-0

14. Grimshaw J. SURGE (The SUrvey Reporting GuidelinE). In: Moher D, Altman DG, Schulz KF, Simera I, Wager E, editors. Guidelines for reporting health research: a user's manual. Hoboken: John Wiley \& Sons; 2014. p. 206-13.

15. Vignola RC, Tucci AM. Adaptation and validation of the depression, anxiety and stress scale (DASS) to Brazilian Portuguese. J Affect Disord. 2014 Feb;155:104-9. https://doi.org/10.1016/j.jad.2013.10.031

16. Lovibond SH, Lovibond PF. Manual for the depression anxiety stress scales. 4th ed. Sidney: Psychology Foundation; 2004.

17. Moraes RR, Correa MB, Queiroz AB, Daneris A, Lopes JP, Pereira-Cenci T, et al. COVID-19 challenges to dentistry in the new pandemic epicenter: Brazil. PLoS One. 2020 Nov;15(11):e0242251. https://doi.org/10.1371/journal.pone.0242251

18. Kalmbach DA, Pillai V, Roth T, Drake CL. The interplay between daily affect and sleep: a 2-week study of young women. J Sleep Res. 2014 Dec;23(6):636-45. https://doi.org/10.1111/jsr.12190

19. Plumb TR, Peachey JT, Zelman DC. Sleep disturbance is common among servicemembers and veterans of Operations Enduring Freedom and Iraqi Freedom. Psychol Serv. 2014 May;11(2):209-19. https://doi.org/10.1037/a0034958

20. Almojali Al, Almalki SA, Alothman AS, Masuadi EM, Alaqeel MK. The prevalence and association of stress with sleep quality among medical students. J Epidemiol Glob Health. 2017 Sep;7(3):169-74. https://doi.org/10.1016/i.jegh.2017.04.005

21. Meerlo P, Sgoifo A, Suchecki D. Restricted and disrupted sleep: effects on autonomic function, neuroendocrine stress systems and stress responsivity. Sleep Med Rev. 2008 Jun;12(3):197-210. https://doi.org/10.1016/i.smrv.2007.07.007

22. Vindegaard N, Benros ME. COVID-19 pandemic and mental health consequences: systematic review of the current evidence. Brain Behav Immun. 2020 Oct;89:531-42. https://doi.org/10.1016/i.bbi.2020.05.048

23. Shacham M, Hamama-Raz Y, Kolerman R, Mijiritsky O, Ben-Ezra M, Mijiritsky E. COVID-19 factors and psychological factors associated with elevated psychological distress among dentists and dental hygienists in Israel. Int J Environ Res Public Health. 2020 Apr;17(8):E2900. https://doi.org/10.3390/ijerph17082900

24. Consolo U, Bellini P, Bencivenni D, lani C, Checchi V. Epidemiological aspects and psychological reactions to COVID-19 of dental practitioners in the Northern Italy Districts of Modena and Reggio Emilia. Int J Environ Res Public Health. 2020 May;17(10):E3459. https://doi.org/10.3390/ijerph17103459

25. Bertolazi AN, Fagondes SC, Hoff LS, Dartora EG, Miozzo IC, Barba ME, et al. Validation of the Brazilian Portuguese version of the Pittsburgh Sleep Quality Index. Sleep Med. 2011 Jan;12(1):70-5. https://doi.org/10.1016/i.sleep.2010.04.020

26. Martínez-de-Quel O, Suárez-Iglesias D, López-Flores M, Pérez CA. Physical activity, dietary habits and sleep quality before and during COVID-19 lockdown: a longitudinal study. Appetite. 2021 Mar;158:105019. https://doi.org/10.1016/i.appet.2020.105019

27. Arora T, Grey I. Health behaviour changes during COVID-19 and the potential consequences: a mini-review. J Health Psychol. 2020 Aug;25(9):1155-63. https://doi.org/10.1177/1359105320937053 
28. Ammar A, Brach M, Trabelsi K, Chtourou H, Boukhris O, Masmoudi L, et al. Effects of COVID-19 home confinement on eating behaviour and physical activity: results of the ECLB-COVID19 International Online Survey. Nutrients. 2020 May;12(6):E1583. https://doi.org/10.3390/nu12061583

29. Brazil. Lei n ${ }^{\circ} 13.979$, de 5 de fevereiro de 2020. Dispõe sobre as medidas para enfrentamento da emergência de saúde pública de importância internacional decorrente do coronavírus responsável pelo surto de 2019. Diário Oficial União, Brasília, DF, 2020 Feb 7.

30. Ribeiro F, Leist A. Who is going to pay the price of Covid-19? Reflections about an unequal Brazil. Int J Equity Health. 2020 Jun;19(1):91. https://doi.org/10.1186/s12939-020-01207-2

31. Lancet. COVID-19 in Brazil: "So what?". Lancet. 2020 May;395(10235):1461. https://doi.org/10.1016/S0140-6736(20)31095-3

32. Goodman WK, Geiger AM, Wolf JM. Leisure activities are linked to mental health benefits by providing time structure: comparing employed, unemployed and homemakers. J Epidemiol Community Health. 2017 Jan;71(1):4-11. https://doi.org/10.1136/jech-2016-207260

33. Takeda F, Noguchi H, Monma T, Tamiya N. How possibly do leisure and social activities impact mental health of middle-aged adults in Japan?: An evidence from a National Longitudinal Survey. PLoS One. 2015 Oct;10(10):e0139777. https://doi.org/10.1371/journal.pone.0139777

34. Wang $C$, Pan R, Wan X, Tan Y, Xu L, Ho CS, et al. Immediate psychological responses and associated factors during the initial stage of the 2019 Coronavirus Disease (COVID-19) epidemic among the general population in China. Int J Environ Res Public Health. 2020 Mar;17(5):E1729. https://doi.org/10.3390/ijerph17051729

35. Hollander-Gijsman ME, Wardenaar KJ, e Beurs E, Wee NJ, Mooijaart A, Buuren S, et al. Distinguishing symptom dimensions of depression and anxiety: an integrative approach. J Affect Disord. 2012 Feb;136(3):693-701. https://doi.org/10.1016/i.jad.2011.10.005

36. Kehne JH, Cain CK. Therapeutic utility of non-peptidic CRF1 receptor antagonists in anxiety, depression, and stress-related disorders: evidence from animal models. Pharmacol Ther. 2010 Dec;128(3):460-87. https://doi.org/10.1016/i.pharmthera.2010.08.011

37. Apóstolo JL. Depressão, ansiedade e stress. In: Apóstolo JL, editor. O conforto pelas imagens mentais na depressão ansiedade e estresse. Coimbra: Imprensa da Universidade de Coimbra; 2010. https://doi.org/10.14195/978-989-26-0036-9

38. Apóstolo JL, Figueiredo MH, Mendes AC, Rodrigues MA. Depression, anxiety and stress in primary health care users. Rev Latino-Am Enfermagem. 2011 Mar-Apr;19(2):348-53. https://doi.org/10.1590/S0104-11692011000200017

39. Stroud CB, Davila J, Moyer A. The relationship between stress and depression in first onsets versus recurrences: a meta-analytic review. J Abnorm Psychol. 2008 Feb;117(1):206-13. https://doi.org/10.1037/0021-843X.117.1.206

40. Kvam S, Kleppe CL, Nordhus IH, Hovland A. Exercise as a treatment for depression: a meta-analysis. J Affect Disord. 2016 Sep;202:67-86. https://doi.org/10.1016/i.jad.2016.03.063

41. Cavalcante JR, Cardoso-Dos-Santos AC, Bremm JM, Lobo AP, Macário EM, Oliveira WK, et al. COVID-19 in Brazil: evolution of the epidemic up until epidemiological week 20 of 2020. Epidemiol Serv Saude. 2020;29(4):e2020376. https://doi.org/10.5123/S1679-49742020000400010

42. Barberia LG, Gómez EJ. Political and institutional perils of Brazil's COVID-19 crisis. Lancet. 2020 Aug;396(10248):367-8. https://doi.org/10.1016/S0140-6736(20)31681-0 